\title{
Biosynthesis of platelet-activating factor by two-cell mouse embryos
}

\author{
X. E. Wells and C. O'Neill* \\ Human Reproduction Unit, Departments of Physiology, and Obstetrics and Gynaecology, \\ The University of Sydney, Royal North Shore Hospital of Sydney, St Leonards, NSW, \\ 2065 Australia
}

\begin{abstract}
Summary. Incubation of two-cell mouse embryos with a range of radiolabelled compounds resulted in the incorporation of label into platelet-activating factor (PAF; 1-O-alkyl-2-acetyl-sn-glycero-3-phosphocholine) in the culture media. The demonstration that known precursors $\left(\left[1-{ }^{14} \mathrm{C}\right]\right.$ hexadecanol, $\left[1-{ }^{3} \mathrm{H}\right]$ hexadecanol, $1-O$ [alkyl-1'2'- $\left.{ }^{3} \mathrm{H}\right]$ lyso-PAF, 1-O-[alkyl-1' $\left.2^{\prime}-{ }^{3} \mathrm{H}\right]$ acetyl-glycerol and [methyl- $\left.{ }^{3} \mathrm{H}\right]$ choline chloride) were incorporated into PAF showed that embryo-derived PAF biosynthesis occurred via pathways present in other PAF-producing cells. The enzyme responsible for the formation of the ether linkage of the PAF molecule, alkyl-dihydroxyacetonephosphate synthase, was present in the preimplantation embryo as $\left[1-{ }^{3} \mathrm{H}\right]$ hexadecanol was incorporated into PAF. Incorporation of label from alkylacetylglycerol and choline chloride into lyso-PAF was also observed, suggesting a role for lyso-PAF in the metabolism of embryo-derived PAF. Incubation of embryos with each of three $\left[{ }^{14} \mathrm{C}\right]$ carbohydrate energy substrates resulted in the incorporation of label into PAF in culture media, indicating that the composition of embryo culture media is important in the synthesis of PAF precursors. Incorporation of label from $\left[2-{ }^{14} \mathrm{C}\right]$ pyruvate was greatest and is consistent with the suggestion that pyruvate is the major energy source at the two-cell stage of development. $\mathrm{L}-\left[\mathrm{U}-{ }^{14} \mathrm{C}\right]$ Lactate was also incorporated into embryo-derived PAF, but the mean amount incorporated relative to the concentration of labelled substrate in the medium was 40 times less. The incorporation of $D-[U$ ${ }^{14} \mathrm{C}$ ]glucose into PAF was 2405 times less than that from pyruvate, relative to the concentration in the medium.
\end{abstract}

Keywords: embryo; platelet-activating factor; mouse

\section{Introduction}

Preimplantation embryos of mice (O'Neill, 1985), humans (Collier et al., 1988, 1990) and sheep (Battye et al., 1991) secrete platelet-activating factor (PAF; 1-O-alkyl-2-acetyl-sn-glycero-3phosphocholine), which is detected in culture media. The detection of embryo-derived PAF in human embryo culture media created by in vitro fertilization may be positively associated with their pregnancy potential after embryo transfer (O'Neill et al., 1987) or pregnancy outcome (Punjabi et al., 1990). PAF appears to act as an autocrine mediator of embryo development (O'Neill et al., 1989a; Ryan et al., 1990a, b) and its activity may be essential for the establishment and maintenance of pregnancy (Spinks et al., 1988, 1990; O'Neill et al., 1990) although this has been questioned by some (Milligan \& Finn, 1990).

Production of PAF by the embryo in culture media ranges from 4.8 to $385.8 \mathrm{ng}$ PAF per embryo per $24 \mathrm{~h}$ for human embryos created by in vitro fertilization, and from 0.8 to $16.9 \mathrm{ng}$ PAF

*Corresponding author. 
per embryo per $24 \mathrm{~h}$ for mouse embryos (Collier et al., 1988). This high output suggests that preimplantation embryos may produce PAF by synthesis de novo. A characteristic feature of embryo-derived PAF production has been the great variability in the amount secreted by embryos (O’Neill \& Saunders, 1984; Collier et al., 1988, 1990; Punjabi et al., 1990; Ammit \& O’Neill, 1991; Battye et al., 1991). This appears to be exacerbated by the effects of culture (Ryan et al., 1989).

This work investigated the ability of two-cell mouse embryos to convert various radiolabelled precursors into embryo-derived PAF to ascertain their role in its synthesis. Two aspects of embryoderived PAF production were investigated.

First, the role of known PAF synthesis intermediates in other cells in embryo-derived PAF production was examined. From studies in different types of cell, pathways of PAF biosynthesis have been well documented; these are the so-called 'de novo pathway' (Fig. 1, reactions VIII to X) and the 'membrane-remodelling' pathway (Fig. 1, reactions VI and VII) (reviewed Snyder, 1985, 1987 , 1990). Both pathways diverge from a common precursor, 1- $O$-alkyl-2-lyso-sn-glycero-3phosphate, which is initially formed from acyl-dihydroxyacetone-phosphate (acyl-DHAP) and a long-chain alcohol (Fig. 1, reactions I and II). The two pathways may be linked by the PAF cycle (Fig. 1, reactions VI, VII, X, XI and XII). It has also been suggested that 1-O-alkyl-2-acetyl-snglycerol may be converted into 1-O-alkyl-2-acyl-sn-glycero-3-phosphocholine via a retroconversion/ de novo pathway of ether lipid biosynthesis (Fig. 1, reactions IX and VIII are reversed, followed by reactions III, IV, V) and subsequently used for biosynthesis of PAF via the membrane remodelling pathway (Lee et al., 1990).

Second, the role of energy substrates in embryo culture media in PAF production of embryos was studied. Empirical studies over many years have helped to define minimal requirements for the development of the preimplantation embryo in vitro. Preimplantation embryos use several carbohydrates. Pyruvate alone, or pyruvate and lactate together, can support growth of the early embryo, whereas glucose may act as the sole energy source from the eight-cell stage of development (reviewed Kaye, 1986). Dihydroxyacetone phosphate (DHAP) and acetyl-CoA are important PAF substrates (Fig. 1). The three carbohydrates might be converted into DHAP via glycolysis, gluconeogenesis or the pentose phosphate pathway. DHAP contributes to the glycerol backbone of the PAF molecule via its conversion to acyl-DHAP by DHAP-acyl transferase (EC 2.3.1.42). Acyl-DHAP is then converted to alkyl-DHAP by alkyl-DHAP synthase (Fig. 1, reaction I). AcetylCoA is also necessary for PAF production and it contributes to the acetyl moiety on the second carbon of the molecule and also to the synthesis of the alkyl chain via long chain acyl groups. Pyruvate may be converted directly into acetyl-CoA by the pyruvate dehydrogenase complex, or indirectly from lactate and glucose, via pyruvate. Acetyl-CoA may be directly incorporated into PAF either by acetyl-CoA:1-O-alkyl-lyso-sn-glycero-3-phosphate acetyltransferase or acetylCoA:1-O-alkyl-lyso-sn-glycero-3-phosphocholine acetyltransferase (Fig. 1, reactions VIII and VII, respectively).

\section{Materials and Methods}

\section{Chemicals}

1- $O$-[Hexadecyl-1'-2'- $\left.{ }^{3} \mathrm{H}(\mathrm{N})\right]-2$-acetyl-sn-glyceryl-3-phosphocholine $\left(\left[{ }^{3} \mathrm{H}\right] \mathrm{PAF}\right.$; sp. act. $\left.2220 \cdot 0 \mathrm{GBq} \mathrm{mmol}^{-1}\right)$, 1-O-[alkyl-1 $\left.1^{\prime}-2^{\prime}-{ }^{3} \mathrm{H}\right]$-sn-glyceryl-3-phosphocholine $\left(\left[{ }^{3} \mathrm{H}\right]\right.$ lyso-PAF; sp. act. $\left.1924 \cdot 0 \mathrm{GBq} \mathrm{mmol}{ }^{-1}\right)$ and $\left[2-{ }^{14} \mathrm{C}\right]$ pyruvic acid, sodium salt (sp. act. $0.22 \mathrm{GBq} \mathrm{mmol}^{-1}$ ) were supplied by NEN (Wilmington, DE, USA). Sigma Chemical Co., St Louis, MO, USA, supplied $\left[1-^{14} \mathrm{C}\right]$ hexadecanol (sp. act. $395.9 \mathrm{MBq} \mathrm{mmol}^{-1}$ ) and $\left[1-^{14} \mathrm{C}\right]$ octadecanol (sp. act. $181 \cdot 3 \mathrm{MBq} \mathrm{mmol}{ }^{-1} \cdot\left[1-{ }^{3} \mathrm{H}\right] \mathrm{Hexadecanol}$ (sp. act. $621 \cdot 6 \mathrm{MBq} \mathrm{mmol}^{-1}$ ) was a gift from $\mathrm{F}$. Snyder, Oak Ridge Associated Universities, Tennessee, USA. Amersham, Buckinghamshire, UK, supplied [methyl- ${ }^{3} \mathrm{H}$ ]choline chloride (sp. act. $555 \mathrm{GBq} \mathrm{mmol}^{-1}$ ), L-[U- $\left.{ }^{14} \mathrm{C}\right]$ lactic acid, sodium salt (sp. act. $6.25 \mathrm{GBq} \mathrm{mmol}{ }^{-1}$ ) and D-[U- $\left.{ }^{14} \mathrm{C}\right]$ glucose (sp. act. 10.6 GBq mmol ${ }^{-1}$. L- $\alpha$-Lysophosphatidylcholine (LPC; soybean), L- $\alpha$-phosphatidylcholine (PC; egg yolk), $\mathbf{L}-\alpha$-phosphatidylethanolamine (PE; bovine brain) and sphingomyeline (SPH; egg yolk) were purchased from Sigma Chemical Co. All organic solvents were High Performance Liquid Chromatography (HPLC) grade (BDH, Poole, UK). Phospholipase C (Bacillus cereus, EC 3.1.4.3, grade I) was purchased from Boehringer Mannheim, Germany. Embryo culture medium contained cell culture grade chemicals from Sigma Chemical Co. 

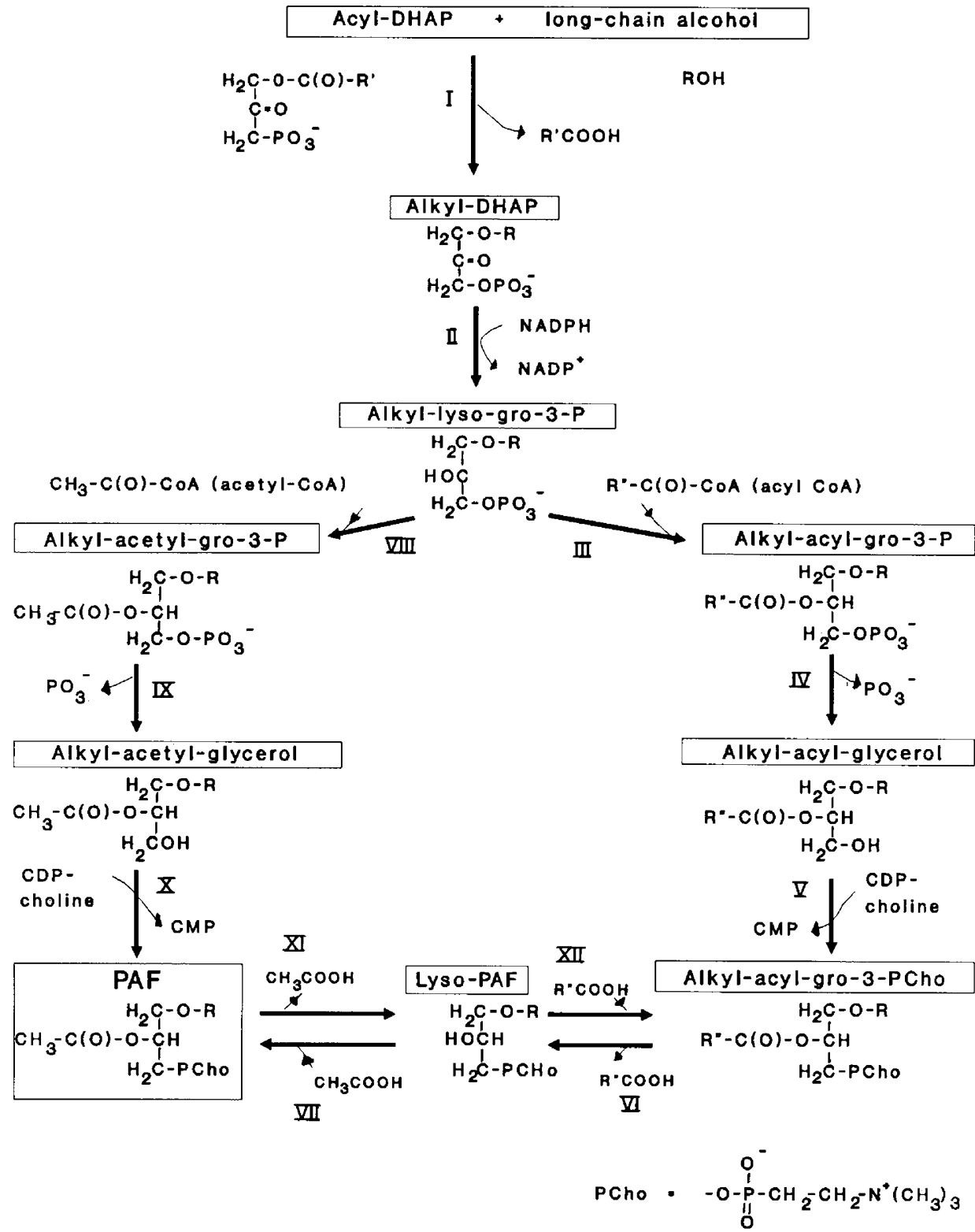

Fig. 1. Biosynthesis of platelet-activating factor. Pathways of PAF biosynthesis have been reviewed by Snyder $(1985,1987,1990)$. Enzymes involved in the formation of PAF are: I. Alkyl-DHAP synthase (EC 2.5.1.26); II. NADPH:alkyl-DHAP oxidoreductase (EC 1.1.1.101); III. Acyl-CoA:alkyl-lyso-glycero-3-P acyltransferase (EC 2.3.1.63); IV. Alkyl-acyl-glycero-P phosphohydrolase; V. CDP-choline:alkyl-acyl-glycerocholinephosphotransferase (EC 2.7.8.2); VI. Phospholipase $\mathrm{A}_{2}$ or CoA-independent transacylase (Uemura et al., 1991); VII. AcetylCoA:alkyl-lyso-glycero-PCho acetyltransferase (EC 2.3.1.67); VIII. Acetyl CoA:alkyl-lysoglycero-3-P acetyltransferase; IX. Alkyl-acetyl-glycero-3-P phosphohydrolase; X. CDP-choline: lkyl-acetyl-glycerol cholinephosphotransferase (EC 2.7.8.16).

The membrane-remodelling pathway consists of reactions VI and VII. The de novo pathway consists of reactions VII-X. Enzymes involved in the PAF cycle: VI; VII; and XI: Alkyl-acetylglycerol-3-PCho acetylhydrolase (EC 3.1.1.48); XII: Acyl-CoA acyltransferase (EC 2.3.1.23), or CoA-independent and CoA-dependent transacylases. P: phosphate; PCho: phosphocholine; Gro: glycero. 


\section{Preparation of 1-O-[Hexadecyl-1'-2'- $\left.{ }^{3} \mathrm{H}(\mathrm{N})\right]$-2-acetyl-sn-glycerol $\left({ }^{3} \mathrm{H} \mid \mathrm{hexadecylacetylglycerol}\right)$}

$\left[{ }^{3} \mathrm{H}\right]$ Hexadecylacetylglycerol (sp. act. $2220 \cdot 0 \mathrm{GBq} \mathrm{mmol}^{-1}$ ) was prepared by phospholipase $\mathrm{C}$ hydrolysis of $\left[{ }^{3} \mathrm{H}\right] \mathrm{PAF}$ (Mavis et al., 1972) and purified by thin layer chromatography (TLC) as described by Renooij \& Snyder (1981) on silica gel 60 plates (E. Merck, Darmstadt, Germany) with a solvent system of $\mathrm{CHCl}_{3}: \mathrm{CH}_{3} \mathrm{OH}(98: 1 \cdot 5, \mathrm{v} / \mathrm{v})$. 1-O-Hexadecyl-2-acetyl-sn-glycerol (Nova Biochem AG, Laufelfingen, Switzerland) was used as the standard and identified by spraying the plate with a solution of $0.025 \%$ Rhodamine $6 \mathrm{G}$ (Sigma) in ethanol and visualized under ultraviolet light. $\left[{ }^{3} \mathrm{H}\right] \mathrm{Hexadecylacetylglycerol} \mathrm{was} \mathrm{extracted} \mathrm{from} \mathrm{the} \mathrm{plate} \mathrm{by} \mathrm{scraping} \mathrm{the} \mathrm{area} \mathrm{comigrating} \mathrm{with}$ standard hexadecylacetylglycerol and eluted as previously described (Renooij \& Snyder, 1981). Purity was determined to be $97.5 \%$ by TLC.

\section{Embryo collection and culture}

Random-bred Swiss albino mice of the Quackenbush strain (Qs; Department of Veterinary Physiology, University of Sydney, NSW, Australia), 6-8 weeks old, were superovulated by intraperitoneal (i.p.) injection of 10 iu pregnant mares' serum gonadotrophin (Folligon: Intervet International, Boxmeer, Netherlands) followed $48 \mathrm{~h}$ later by an i.p. injection of $10 \mathrm{iu}$ human chorionic gonadotrophin (hCG; Chorulon: Intervet). They were paired with males of proven fertility overnight and the presence of a copulation plug was designated day $I$ of pregnancy.

Embryos at the two-cell stage were recovered by flushing the oviducts of mated animals $38-40 \mathrm{~h}$ after hCG injection (day 2). Flushing was performed with Hepes-buffered human tubal fluid medium (6.508 mmol Hepes $^{-1}$, $101.6 \mathrm{mmol}-\mathrm{NaCl} \quad 1^{-1}, 4.69 \mathrm{mmol}-\mathrm{KCl} \quad 1^{-1}, \quad 0.20 \mathrm{mmol}-\mathrm{MgSO}_{4} 1^{-1}, \quad 0.37 \mathrm{mmol} \quad \mathrm{KH}_{2} \mathrm{PO}_{4} 1^{-1}, 2.04 \mathrm{mmol}-$ $\mathrm{CaCl}_{2} .2 \mathrm{H}_{2} \mathrm{Ol}^{-1}, 2.78 \mathrm{mmol}$ glucose $1^{-1}, 21.4 \mathrm{mmol}$ sodium lactate $1^{-1}, 0.33 \mathrm{mmol}$ sodium pyruvate $\mathrm{l}^{-1}, 4.0 \mathrm{mmol}$ $\mathrm{NaHCO}_{3} \mathrm{I}^{-1}, 100 \mathrm{U}$ penicillin $\mathrm{G} \mathrm{ml}^{-1}, 0.001 \% \mathrm{w} / \mathrm{v}$ phenol red, $\mathrm{pH} 7 \cdot 5,280-285 \mathrm{mOsmol}$; Quinn et al., 1985) supplemented with $3 \mathrm{mg}$ bovine serum albumin (BSA; Pentex, bovine albumin, crystallized, Miles Diagnostics, Kankakee, IL, USA) $\mathrm{ml}^{-1}$. Embryos were washed twice in bicarbonate-buffered human tubal fluid medium (which is the same as Hepes-buffered human tubal fluid medium except that Hepes is replaced with $21 \cdot 0 \mathrm{mmol}-\mathrm{NaHCO}_{3} \mathrm{I}^{-1}$; Quinn $e t$ al., 1985) containing $3 \mathrm{mg} \mathrm{BSA} \mathrm{ml}{ }^{-1}$ (HTFM + BSA). Embryos from all females were pooled and then randomly divided into groups of $30-40$ and cultured in an atmosphere of $5 \% \mathrm{CO}_{2}$ in air at $37^{\circ} \mathrm{C}$ for various periods in $5 \mathrm{ml}$ Falcon tissue culture tubes (Becton Dickinson Co., Rutherford, NJ, USA) containing $0.7 \mathrm{ml}$ pre-equilibrated HTFM plus BSA and the appropriate radiolabelled compound. Cultures were performed in duplicate for each time point.

Labelled HTFM plus BSA was prepared by aliquoting the appropriate amount of radiolabelled compound into a siliconized sterile tube. Solvent was removed under a continuous stream of nitrogen at $25^{\circ} \mathrm{C}$ and extended with HTFM plus BSA to give the required concentration of radiolabel. Culture tubes containing radiolabel but no embryos were also set up, incubated, frozen, extracted and used as blanks. When culture was performed with radiolabelled carbohydrates, there was a difference in the carbohydrate composition of HTFM plus BSA. It was carbohydrate-free except for the addition of $\left[2-{ }^{14} \mathrm{C}\right]$ pyruvate $\left(124 \mu \mathrm{mol}^{-1}\right)$ or L-[U- $\left.{ }^{14} \mathrm{C}\right]$ lactate $\left(170 \mu \mathrm{mol} 1^{-1}\right)$; or glucose-free except for the addition of $\mathrm{D}-\left[\mathrm{U}-{ }^{14} \mathrm{C}\right] \mathrm{glucose}\left(115 \mu \mathrm{mol} \mathrm{I}^{-1}\right)$.

After culture, embryos were removed, the media gassed with $5 \% \mathrm{CO}_{2}$ in air and the culture media immediately frozen. Embryos were washed twice in HTFM plus BSA and cultured uninterrupted for up to $72 \mathrm{~h}$ in $0.7 \mathrm{ml}$ of HTFM plus BSA to assess the effect of exposure to radiolabel on subsequent embryo development. Embryos that were not exposed to radiolabel were also cultured and acted as controls.

\section{Extraction and HPLC of labelled embryo-derived PAF from culture media}

The extraction procedure was based on the method described by Collier et al. (1988), with minor modifications. The medium to be extracted $(0.4 \mathrm{ml})$ was added dropwise to $7.6 \mathrm{ml}$ of methanol in siliconized tubes (Vacutainer, Becton Dickinson Co., Rutherford, NJ, USA) and left for $30 \mathrm{~min}$ at room temperature. Precipitated proteins were removed by centrifugation at $2500 \mathrm{~g}$ for $20 \mathrm{~min}$ at $5^{\circ} \mathrm{C}$. The supernatant was removed and $7.6 \mathrm{ml}$ of chloroform and $6.4 \mathrm{ml}$ of water were added to effect phase separation. The chloroform phase was collected and $0.38 \mathrm{ml}$ of methanol added to clear the solution. Solvent was evaporated from the samples by rotary evaporation and followed by a stream of nitrogen.The residue was resuspended in methanol ( $150 \mu \mathrm{l}$ ) and filtered through a $0.45 \mu \mathrm{m}$ filter (Millipore, Yonezawa, Japan).

Culture media extracts were chromatographed by high performance liquid chromatography (HPLC) as described by Gross \& Sobel (1980) with minor modifications. Samples were applied to a Partisil strong cation exchange (SCX) column, $10 \mu \mathrm{m}, 250 \mathrm{~mm} \times 4.6 \mathrm{~mm}$ (Whatman, Clifton, NJ, USA) and eluted isocratically with a mobile phase of

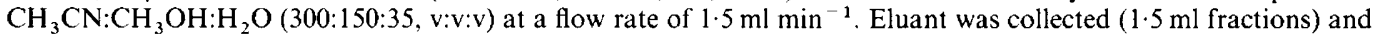
the amount of radioactivity in each fraction was determined by liquid scintillation counting. The distribution of radiolabel throughout the elution profile for each sample was compared with the known distribution of $\left[{ }^{3} \mathrm{H}\right] \mathrm{PAF}$ (Fig. 2). Radiolabelled embryo-derived PAF production was identified as the amount of radioactivity eluted in the same region as $\left.{ }^{3} \mathrm{H}\right] \mathrm{PAF}$ after subtraction of the blank samples (incubations plus radiolabel, minus embryos). Identification of lyso-PAF was performed in the same manner. The elution profiles of a range of phospholipids were examined to ensure that they did not comigrate with PAF (Fig. 2). These standards plus $\left[{ }^{3} \mathrm{H}\right] \mathrm{PAF}$ were routinely chromatographed before and after a series of unknown samples to determine the retention time of PAF. 
$\left[{ }^{3} \mathrm{H}\right]$ PAF could not be used as an internal standard in unknown samples therefore the efficiency of the extraction and HPLC procedure was monitored by the addition of trace amounts of [ $\left.{ }^{3} \mathrm{H}\right]$ PAF (approximately $1000 \mathrm{~d} . \mathrm{p} . \mathrm{m}$.) to duplicate samples of HTFM plus BSA which were processed in parallel with unknown samples. The mean percentage recovery of $\left[{ }^{3} \mathrm{H}\right] \mathrm{PAF}$ was determined and used to correct for the loss of activity during the extraction and chromatography.

\section{Results}

\section{Efficiency of extraction and HPLC of embryo-derived PAF culture media}

The mean overall recovery of a $\left[{ }^{3} \mathrm{H}\right] \mathrm{PAF}$ tracer from HTFM plus BSA by the extraction and HPLC procedure was $61.7 \% \pm 2.9 \%$ (SEM, $n=18$ ). Tracer was recovered from HTFM plus BSA by liquid-liquid extraction ( $\left[{ }^{3} \mathrm{H}\right] \mathrm{PAF}$ recovery in $150 \mu \mathrm{l} \mathrm{CH}_{3} \mathrm{OH}$ ) at $73 \cdot 5 \% \pm 3 \cdot 25 \%$ (SEM, $n=18$ ). Of the amount of $\left[{ }^{3} \mathrm{H}\right] \mathrm{PAF}$ applied to the SCX HPLC column, $82 \cdot 8 \% \pm 0 \cdot 7 \%$ (SEM, $n=14$ ) was recovered. The HPLC elution profiles of a range of phospholipids were examined to ensure that they did not comigrate with PAF (Fig. 2). The percentage of [ $\left.{ }^{3} \mathrm{H}\right] \mathrm{PAF}$ activity remaining after extraction and separation was similar to the recovery of labelled precursors extracted into the $\mathrm{CHCl}_{3}$ phase. The recovery of $\left[{ }^{3} \mathrm{H}\right]$ lyso-PAF, eluted in fractions after PAF (Fig. 2), was $58 \cdot 8 \% \pm 1 \cdot 5 \%(\mathrm{SEM}, n=12) \cdot\left[1-{ }^{14} \mathrm{C}\right]$ Hexadecanol, $\left[1-{ }^{3} \mathrm{H}\right]$ hexadecanol, $\left[1-{ }^{14} \mathrm{C}\right]$ octadecanol and $\left[{ }^{3} \mathrm{H}\right]$ hexadecylacetylglycerol were all eluted in the solvent front of the chromatogram and the recoveries were $66 \cdot 6 \% \pm 1 \cdot 0 \%$ (SEM, $n=11$ ), $58 \cdot 55 \% \pm 2 \cdot 6 \%$ (SEM, $n=10), 69 \cdot 3 \% \pm 2 \cdot 5 \%$ (SEM, $n=12$ ) and $54.8 \% \pm 1 \cdot 1 \%$ (SEM, $n=12$ ), respectively. The other radiolabelled precursors tested remained in the water phase during the extraction procedure.

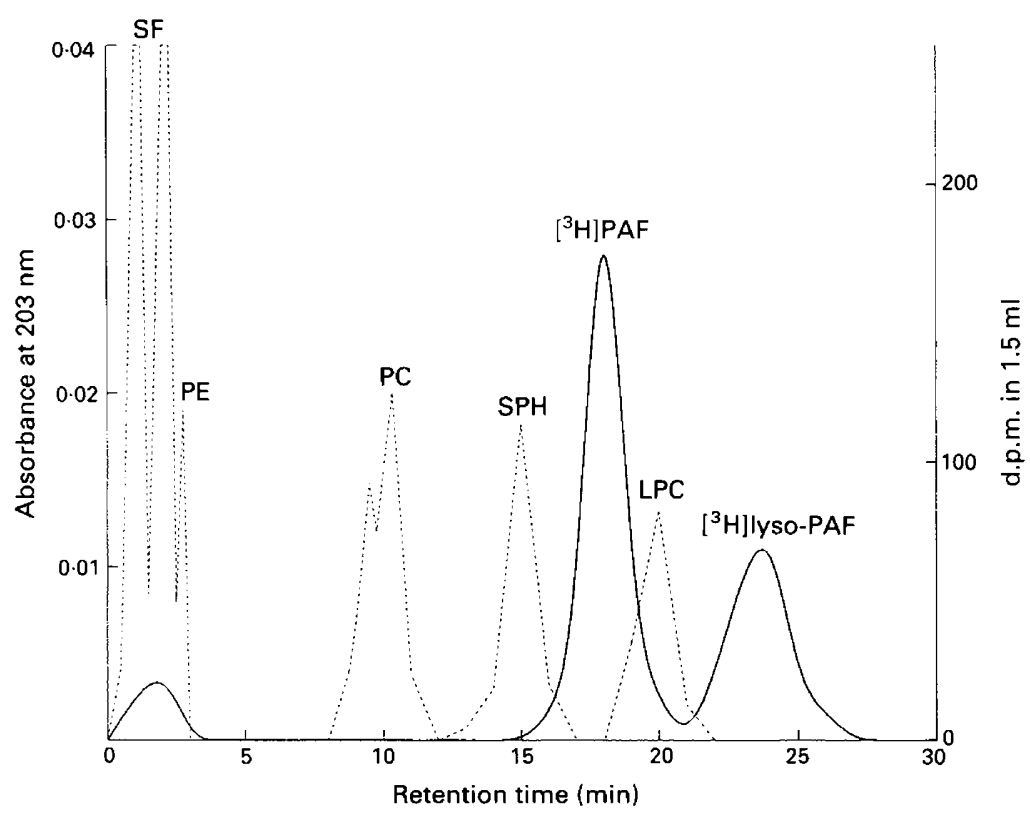

Fig. 2. Separation of phospholipids by HPLC. Methanol $(100 \mu \mathrm{l})$ containing $\left[{ }^{3} \mathrm{H}\right]$ plateletactivating factor (PAF), $\left[{ }^{3} \mathrm{H}\right]$ lyso-PAF, $1 \mu \mathrm{g} \mathrm{L}-\alpha$-phosphatidylethanolamine (PE) and $10 \mu \mathrm{g}$ each of $\mathrm{L}-\alpha$-phosphatidylcholine (PC), sphingomyelin (SPH) and $\mathrm{L}-\alpha-1$ ysophosphatidylcholine (LPC) was injected onto a Partisil SCX column, $10 \mu \mathrm{m}, 250 \mathrm{~mm} \times 4.6 \mathrm{~mm}$ (Whatman, Clifton, NJ, USA). The column was eluted with a mixture of $\mathrm{CH}_{3} \mathrm{CN}: \mathrm{CH}_{3} \mathrm{OH}: \mathrm{H}_{2} \mathrm{O}(300: 150: 35$, v:v:v) at a flow of $1.5 \mathrm{ml} \mathrm{min}{ }^{-1}$. Standards were identified by absorbance at $203 \mathrm{~nm}(---)$ and liquid scintillation counting (-). SF: solvent front. 
Table 1. Production of label comigrating with platelet-activating factor by two-cell mouse embryos incubated with various radiolabelled compounds

\begin{tabular}{|c|c|c|c|}
\hline Compound & $\begin{array}{l}\text { Concentration } \\
\mathrm{mol} \mathrm{l}^{-1}\end{array}$ & $\begin{array}{l}\text { Percentage conversion of } \\
\text { radiolabelled compound } \\
\text { into PAF in HTFM plus BSA } \\
\text { per } 10 \text { embryos } \\
\text { (mean } \pm \text { SEM) }\end{array}$ & $\begin{array}{l}\text { Percentage of cultures } \\
\text { producing PAF } \\
\text { (PAF positive cultures/ } \\
\text { total cultures) }\end{array}$ \\
\hline$\left[1-{ }^{14} \mathrm{C}\right]$ hexadecanol & $3.0 \times 10^{-5}$ & $0.02 \pm 0.01$ & $50 \%(14 / 28)$ \\
\hline$\left[1-{ }^{3} \mathrm{H}\right]$ hexadecanol & $1.5 \times 10^{-5}$ & $0.015 \pm 0.002$ & $100 \%(8 / 8)$ \\
\hline$\left[1-{ }^{14} \mathrm{C}\right]$ octadecanol & $9.0 \times 10^{-6}$ & $0.43 \pm 0.31$ & $63 \%(5 / 8)$ \\
\hline [methyl- ${ }^{3} \mathrm{H}$ ]choline chloride & $1.72 \times 10^{-10}$ & $0.21 \pm 0.04$ & $46 \%(11 / 24)$ \\
\hline$\left[{ }^{3} \mathrm{H}\right]$ lyso-PAF & $4.9 \times 10^{-11}$ & $0.55 \pm 0.27$ & $68 \%(15 / 22)$ \\
\hline$\left[{ }^{3} \mathrm{H}\right]$ hexadecyl-acetylglycerol & $4.3 \times 10^{-11}$ & $0.32 \pm 0.18$ & $21 \%(5 / 22)$ \\
\hline$\left[2{ }^{14}\right.$ C]pyruvate & $1.24 \times 10^{-4}$ & $1.27 \pm 0.47\left(\times 10^{-3}\right)$ & $58 \%(14 / 24)$ \\
\hline $\mathrm{L}-\left[\mathrm{U}-{ }^{14} \mathrm{C}\right]$ lactate & $1.70 \times 10^{-4}$ & $3 \cdot 18 \pm 1 \cdot 12\left(\times 10^{-5}\right)$ & $39 \%(7 / 18)$ \\
\hline D-[U- ${ }^{14}$ C]glucose & $1.15 \times 10^{-4}$ & $0.53 \pm 0.23\left(\times 10^{-6}\right)$ & $23 \%(7 / 31)$ \\
\hline
\end{tabular}

HTFM: human tubal fluid medium.

\section{Production of labelled products comigrating with PAF in culture media containing two-cell embryos and a radiolabelled compound}

Incubation of two-cell embryos for various periods with $\left[1-{ }^{14} \mathrm{C}\right]$ hexadecanol, $\left[1-{ }^{14} \mathrm{C}\right]$ octadecanol, [1- $\left.{ }^{3} \mathrm{H}\right]$ hexadecanol, [methyl- $\left.{ }^{3} \mathrm{H}\right]$ choline chloride, $\left[{ }^{3} \mathrm{H}\right]$ lyso-PAF, $\left[{ }^{3} \mathrm{H}\right]$ hexadecylacetylglycerol, D$\left[\mathrm{U}-{ }^{14} \mathrm{C}\right] \mathrm{g}$ lucose, L- $\left[\mathrm{U}-{ }^{14} \mathrm{C}\right]$ lactate or $\left[2-{ }^{14} \mathrm{C}\right]$ pyruvate resulted in the production of radiolabelled PAF in the HPLC eluate of extracts of culture media (Table 1).

PAF production from each compound at various time intervals for up to $6 \mathrm{~h}$ was determined. However, there were no significant differences in PAF production with time (Kruskal-Wallis test) and therefore data were pooled for each radiolabelled compound. There was a high degree of variability within and between experiments (Table 1). Experiments where no incorporation of label into PAF (or lyso-PAF) was observed in all of the treatments were not included in the analysis, but the number excluded is indicated in Table 1.

Known intermediates of PAF biosynthetic pathways in other cells $\left[1-{ }^{14} \mathrm{C}\right]$ hexadecanol, $\left[1-{ }^{14} \mathrm{C}\right]$ octadecanol, $\left[1-{ }^{3} \mathrm{H}\right]$ hexadecanol, [methyl- $\left.{ }^{3} \mathrm{H}\right]$ choline chloride, $\left[{ }^{3} \mathrm{H}\right]$ lyso-PAF, $\left[{ }^{3} \mathrm{H}\right]$ hexadecylacetylglycerol; Fig. 1) were all incorporated into embryo-derived PAF (Table 1). Incorporation of $\left[\right.$ methyl $\left.-{ }^{3} \mathrm{H}\right]$ choline chloride, $\left[{ }^{3} \mathrm{H}\right]$ lyso-PAF, $\left[{ }^{3} \mathrm{H}\right]$ hexadecylacetylglycerol were all within the same order of magnitude. The incorporation of $\left[{ }^{3} \mathrm{H}\right]$ into PAF in culture media extracts of embryos incubated with $\left[1-{ }^{3} \mathrm{H}\right]$ hexadecanol $\left(15 \mu \mathrm{mol}^{-1}\right)$ indicated that the long chain alcohol is incorporated into the $O$-alkyl chain of the PAF molecule (Lumb \& Snyder, 1971).

Lyso-PAF production in culture media was observed when embryos were cultured with $\left[{ }^{3} \mathrm{H}\right]$ hexadecylacetylglycerol and $\left[{ }^{3} \mathrm{H}\right.$-methyl $]$ choline chloride. Data presented are the mean of several experiments and the highly variable amounts of radiolabelled PAF that were produced by the twocell mouse embryos from $\left[{ }^{3} \mathrm{H}\right]$ hexadecylacetylglycerol and $\left[{ }^{3} \mathrm{H}\right.$-methyl]choline chloride (Fig. 3 ) are typical of the other compounds tested. There were no significant differences with time (KruskalWallis test) in the amounts of PAF and lyso-PAF produced from either $\left[{ }^{3} \mathrm{H}\right]$ hexadecylacetylglycerol or $\left[{ }^{3} \mathrm{H}\right.$-methyl]choline chloride.

The incorporation of $\left[{ }^{14} \mathrm{C}\right]$ from $\mathrm{D}-\left[\mathrm{U}-{ }^{14} \mathrm{C}\right]$ glucose, $\mathrm{L}-\left[\mathrm{U}-{ }^{14} \mathrm{C}\right]$ lactate or $\left[2-{ }^{14} \mathrm{C}\right]$ pyruvate into embryo-derived PAF was also observed (Table 1). The mean percentage incorporation of $\left[{ }^{14} \mathrm{C}\right]$ pyruvate into PAF detected in the media per 10 embryos relative to the amount of labelled substrate in the medium was 40 and 2405 times greater than the incorporation from lactate and glucose, respectively.

No conversion of any substrate into PAF was observed in the absence of embryos using the culture system described. This was monitored by subtracting the total amount of d.p.m. in the 


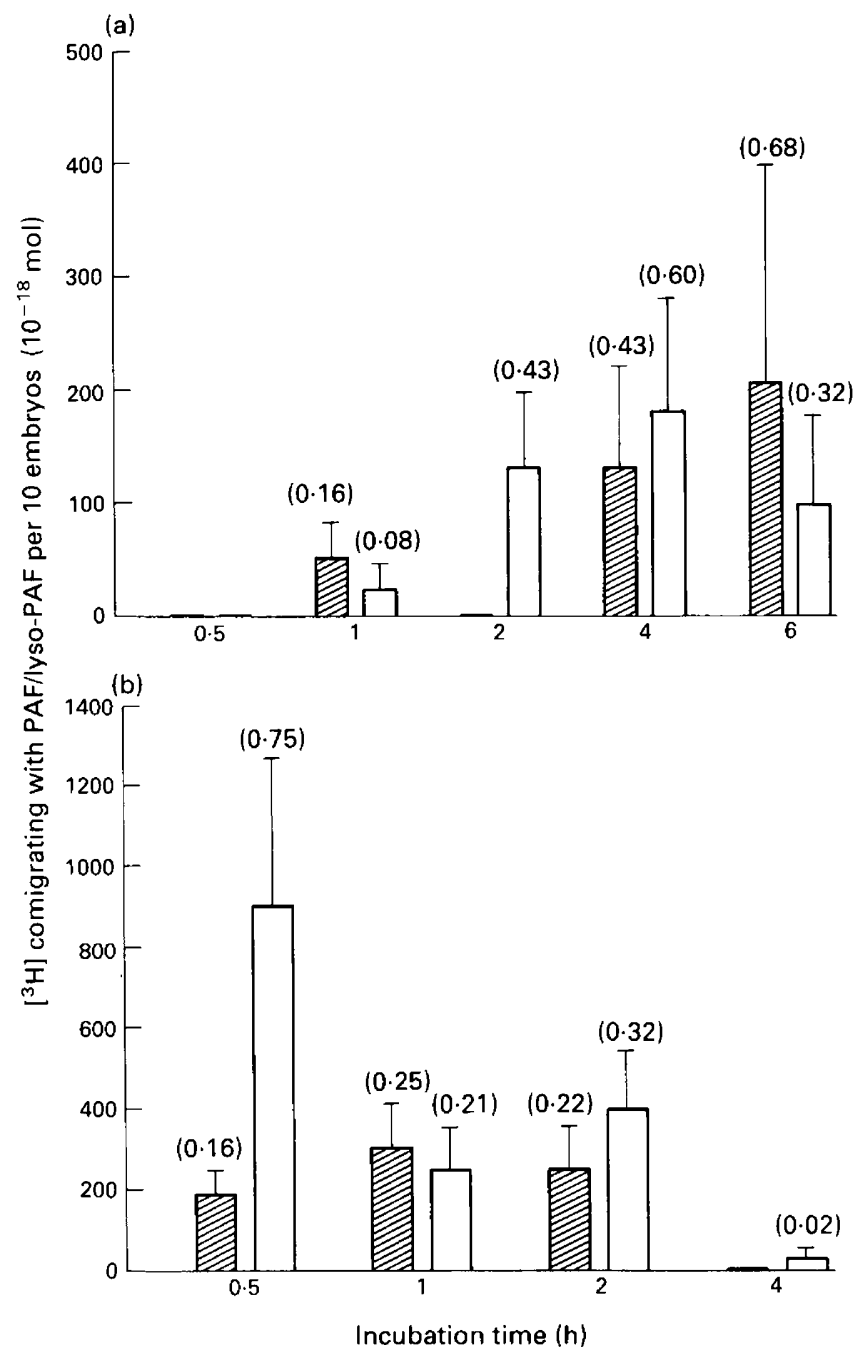

Fig. 3. Incorporation of $\left[{ }^{3} \mathrm{H}\right]$ into platelet-activating factor (PAF; $\left.\square\right)$ and lyso-PAF $(\square)$ in culture media by two-cell embryos incubated with (a) 43 pmol $\left[{ }^{3} \mathrm{H}\right]$ alkylacetylglycerol $]^{-1}$ (sp. act. $2220 \mathrm{GBq} \mathrm{mmol}^{-1}$ ) and (b) $171.6 \mathrm{pmol}\left[\right.$ methyl- ${ }^{3} \mathrm{H}$ ]choline chloride $\mathrm{l}^{-1}$ (sp. act. $555 \mathrm{GBq}$ $\mathrm{mmol}^{-1}$ ). Results are the mean \pm SEM of several experiments and the figures in parentheses above each incubation time are the mean percentage conversion of labelled precursor in the culture media to radiolabelled PAF and lyso-PAF in the culture media per 10 embryos.

PAF-eluting fractions from an equivalent volume of $\mathrm{CH}_{3} \mathrm{OH}$ injected onto the HPLC column from blank samples (plus label, minus embryos).

\section{Effect of culture with radiolabelled compounds on subsequent embryo development}

Culture of two-cell embryos with radiolabelled compounds for up to $6 \mathrm{~h}$ had varying effects on subsequent development to the blastocyst stage. The development rates of embryos cultured for $6 \mathrm{~h}$ with $\left[{ }^{14} \mathrm{C}\right]$ pyruvate, $\left[{ }^{14} \mathrm{C}\right]$ lactate and $\left[{ }^{14} \mathrm{C}\right]$ glucose were $40 \%$ (46 of 116$), 9 \%$ (9 of 96 ) and $0 \cdot 8 \%$ ( 1 of 120 ), respectively. These rates were lower than the corresponding control group developmental 
rates of $53 \%$ ( 37 of 70 ), $45 \%$ (52 of 115 ) and $73 \%$ (84 of 115 ), respectively. The numbers in parentheses indicate the number of embryos developing to expanded blastocysts of the total number of embryos cultured. $\chi^{2}$ analysis of control cultures (negative label) versus positive label cultures for each carbohydrate were $P<0 \cdot 10$ ([ $\left.{ }^{14} \mathrm{C}\right]$ pyruvate) and $P<0.001\left(\left[{ }^{14} \mathrm{C}\right] \mathrm{glucose}\right.$ and $\left[{ }^{14} \mathrm{C}\right]$ lactate). The low development rates of the control group cultures for the $\left[{ }^{14} \mathrm{C}\right]$ pyruvate and $\left[{ }^{14} \mathrm{C}\right]$ lactate experiments were possibly due to the effect of short term culture $(6 \mathrm{~h})$ in carbohydratefree HTFM plus BSA as the development rate of two-cell embryos cultured uninterrupted for $72 \mathrm{~h}$ in carbohydrate-containing HTFM plus BSA was 78\% (108 of 138). This is significantly different from the development rates of control groups from $\left[{ }^{14} \mathrm{C}\right]$ lactate and $\left[{ }^{14} \mathrm{C}\right]$ pyruvate $\left(\chi^{2}\right.$ analysis, $P<0.001)$. However, culture in glucose-free HTFM plus BSA for $6 \mathrm{~h}\left(\left[{ }^{14} \mathrm{C}\right]\right.$ glucose experiment control group) did not significantly affect development rates.

Compared with the control group (negative label), culture of two-cell embryos for $4 \mathrm{~h}$ in the presence of $\left[{ }^{3} \mathrm{H}\right]$ lyso-PAF decreased the rate of further development to the blastocyst stage from $82 \%$ ( 80 of 97 ) to $48 \%$ ( 32 of 67 ) ( $\chi^{2}$ analysis, $P<0.001$ ). The development of two-cell embryos cultured with $\left[{ }^{3} \mathrm{H}\right]$ hexadecylacetylglycerol for $6 \mathrm{~h}$ decreased from $67 \%$ (50 of 75 ; control group) to $51 \%$ (32 of 63) $\left(\chi^{2}\right.$ analysis, $P<0 \cdot 059$ ). Culture with $\left[1-{ }^{14} \mathrm{C}\right]$ hexadecanol for $6 \mathrm{~h}$ and $\left[{ }^{3} \mathrm{H}\right] \mathrm{choline}$ chloride for $4 \mathrm{~h}$ did not effect subsequent development to blastocysts compared with the control groups.

\section{Discussion}

This study used a number of radiolabelled compounds to demonstrate for the first time that the two-cell mouse embryo can synthesize and release PAF when cultured in vitro. Synthesis appears to occur via pathways that occur in other types of cell (Fig. 1), since known intermediates of these pathways, namely lyso-PAF, alkylacetylglycerol, long chain alcohols and choline, were incorporated by the embryo into PAF released into the culture media. It was also demonstrated that the two-cell mouse embryo can convert carbohydrates normally present in culture media (glucose, lactate, pyruvate; Quinn et al., 1985) into embryo-derived PAF suggesting that they are substrates for PAF biosynthesis.

The fact that similar amounts of label are incorporated from $\left[1-{ }^{3} \mathrm{H}\right]$ hexadecanol and $\left[1-{ }^{14} \mathrm{C}\right]$ hexadecanol (Table 1 ) implies that the reaction catalysed by alkyl-DHAP synthase (Lumb \& Snyder, 1971) (Fig. 1, reaction I) is present in the early embryo. The incorporation of this substrate is via this reaction rather than nonspecific incorporation of $\left[{ }^{14} \mathrm{C}\right]$ from hexadecanol into PAF. Long chain alcohols could also be used for plasmalogen formation (Horrocks \& Sharma, 1982) or oxidized to long chain acids (for example by fatty alcohol:NAD ${ }^{+}$oxidoreductase, Lee, 1979) and used in the acyl groups of glycerolipids. These possible routes of incorporation into other lipid classes have not yet been investigated in the preimplantation embryo, but seem unlikely to affect our results as they would not be expected to be secreted by the embryo nor would they comigrate with PAF on HPLC.

The two possible direct precursors of PAF by the de novo and membrane remodelling pathways, alkylacetylglycerol and lyso-PAF, respectively, were converted into PAF in the culture media by the two-cell mouse embryo (Table 1). This may suggest that both pathways are operational in the early embryo. The presence of both pathways has been documented for several types of cell, including endothelial cells (Bussolino et al., 1987) and polymorphonuclear leukocytes (Alonso et al., 1982). The production of lyso-PAF and PAF from alkylacetylglycerol and choline (Fig. 3a, b) by embryos may suggest that the PAF cycle (Fig. 1) is operational, possibly linking the two pathways if they are present. Alternatively, retroconversion of alkylacetylglycerol to 1-O-alkyl-2-acyl-snglycero-3-phosphocholine and its subsequent conversion to PAF via lyso-PAF may occur in the embryo. This pathway is present in rabbit platelets (Lee et al., 1990).

$\left[{ }^{3} \mathrm{H}\right]$ Alkylacetylglycerol was prepared from $\left[{ }^{3} \mathrm{H}\right] \mathrm{PAF}$ by phospholipase $\mathrm{C}$ hydrolysis and purified by TLC. The purity of the preparation was estimated to be $97 \cdot 5 \%$. When greater amounts 
of $\left[{ }^{3} \mathrm{H}\right]$ alkylacetylglycerol (18 500 d.p.m.) than that present in culture media samples were injected onto the column, no label was detected in the HPLC eluate fractions comigrating with PAF. This indicates that the $\left[{ }^{3} \mathrm{H}\right] \mathrm{PAF}$ detected after culture was produced by embryos. Possible contaminants may be 1-O-alkyl-3-acetyl-sn-glycerol and 1-O-alkyl-sn-glycerol (Renooij \& Snyder, 1981) and these would not co-elute with $\left[{ }^{3} \mathrm{H}\right] \mathrm{PAF}$.

The observed incorporation of $\left[{ }^{3} \mathrm{H}\right]$ from $\left[\right.$ methyl- $\left.{ }^{3} \mathrm{H}\right]$ choline chloride into PAF and lyso-PAF (Table 1; Fig. 3b) may occur after its conversion into CDP-choline via choline kinase (EC 2.7.1.32) and choline-phosphate cytidyltransferase (EC 2.7.7.15). Pratt (1980) reported the presence of choline kinase within the preimplantation mouse embryo. In known PAF biosynthetic pathways there are two possible points of choline incorporation (reactions $\mathrm{V}$ and $\mathrm{X}$, Fig. 1).

Glucose, lactate and pyruvate are components of embryo culture media (Quinn et al., 1985) and it has previously been demonstrated that the mouse preimplantation embryo incorporates $\left[{ }^{14} \mathrm{C}\right]$ from $\left[\mathrm{U}-{ }^{14} \mathrm{C}\right]$ glucose (Flynn \& Hillman, 1978) and $\left[2-{ }^{14} \mathrm{C}\right]$ pyruvate (Wales \& Whittingham, 1970) into lipids within the embryo. In this report we demonstrate that the two-cell mouse embryo can convert glucose, lactate and pyruvate into embryo-derived PAF in culture media (Table 1) suggesting that synthesis from these compounds may be de novo. Greater amounts of $\left[{ }^{14} \mathrm{C}\right]$ from pyruvate were incorporated into PAF than that from glucose and lactate by two-cell embryos (Table 1). This observation is consistent with the suggestion that pyruvate is the major energy substrate at this developmental stage (Brinster, 1967, 1969; Leese \& Barton, 1984). Pyruvate alone in embryo culture media will support embryo growth from the two-cell to the blastocyst to a greater extent than lactate alone (Brinster, 1965; Wales \& Whittingham, 1973). Glucose alone in media will not support the development of the two-cell embryo (Brinster, 1965). Incorporation of glucose, lactate and pyruvate into embryo-derived PAF may be via their conversion to the PAF substrates DHAP and acetyl-CoA as briefly discussed earlier in this report and by O'Neill et al. (1989b, 1990). Another possible route of incorporation of carbon from carbohydrates into PAF is through their metabolism to choline via serine.

The low levels of incorporation of $\left[{ }^{14} \mathrm{C}\right]$ from $\left[{ }^{14} \mathrm{C}\right]$ glucose into PAF in culture media by embryos (Table 1) may be due to the low levels of glucose uptake (Leese \& Barton, 1984) at this developmental stage and because of its subsequent diversion to incorporation into glycogen (Pike \& Wales, 1982). Since glucose becomes the predominant energy source after the morula stages (Leese \& Barton, 1984), glucose might become a more important substrate for PAF production at later developmental stages. Pyruvate and lactate were included in culture media for experiments measuring PAF production from $\left[{ }^{14} \mathrm{C}\right]$ glucose in this study because two-cell mouse embryos do not survive culture in medium containing glucose as the sole energy source (Pike \& Wales, 1982) and pyruvate and lactate are necessary for the growth of the early embryo (Kaye, 1986). This study confirms this as culture for $6 \mathrm{~h}$ in carbohydrate-free HTFM (embryos cultured in the absence of label; $\left[{ }^{14} \mathrm{C}\right]$ lactate and $\left[{ }^{14} \mathrm{C}\right]$ pyruvate experiments) resulted in lower growth rates than culture in glucose-free HTFM for $6 \mathrm{~h}$ (embryos cultured in the absence of label; $\left[{ }^{14} \mathrm{C}\right]$ glucose experiment).

The biochemical approach described in this report confirms previous observations that secretion of biologically active embryo-derived PAF is highly variable (O'Neill \& Saunders, 1984; Collier et al., 1988, 1990; Punjabi et al., 1990; Ammit \& O'Neill, 1991; Battye et al., 1991). Overall, radiolabelled embryo-derived PAF was detected in $42.5 \%$ of cultures (Table 1). It was sometimes observed in this study that all the treatments set up for a single experiment did not produce PAF indicating the presence of an undefined element(s) within the whole system not conducive to embryo-derived PAF biosynthesis. Experiments where no incorporation of label into PAF or lyso-PAF was observed in all of the treatments were therefore not included in analysis. The control of embryo-derived PAF production is not known and techniques reported here will allow the mechanisms of control and the causes of variable secretory activity in vitro to be further investigated.

The wide concentration range of PAF produced by embryo cultures may be exacerbated by the variability associated with extraction and purification procedures. In this report the recovery of $\left[{ }^{3} \mathrm{H}\right] \mathrm{PAF}$ tracer was more consistent and higher than in a previous study (Collier et al., 1988), possibly due to the better recovery from HPLC, compared with thin layer chromatography. The 
fact that considerable variability in the amount of embryo-derived PAF still occurred with the improved recovery after purification, suggests that this phenomenon is not an artifact of its purification.

The techniques developed and described in this study identify radiolabelled embryo-derived PAF production by comparison of the retention time to $\left[{ }^{3} \mathrm{H}\right] \mathrm{PAF}$ standard in HPLC eluates and the monitoring of the retention times of PAF and other phospholipids was rigorous and routine throughout the entire study. Whereas none of the major phospholipid classes eluted with PAF on the HPLC system (Fig. 2), the absolute structural identity of radiolabelled embryo-derived PAF could not be proved owing to the small amount of material available.

Radiation is toxic to preimplantation embryos (Sherman, 1979; Domon, 1980) and the extent of toxicity differed between compounds used in this study. The incorporation of label from carbohydrates into PAF by the embryos required much higher concentrations (and hence radioactivity) of compounds in media than was required of the more immediate precursors. This higher level of radiation in the carbohydrate cultures decreased the developmental rates to a greater extent. This may account for the lower levels of PAF produced from these compounds since PAF production may be positively correlated with embryo viability (O'Neill et al., 1987).

This study showed that two-cell mouse embryos actively synthesize PAF. Synthesis appears to occur via known pathways. The composition of embryo culture media may have a role in synthesis as components were converted into embryo-derived PAF indicating that the synthesis of important PAF precursors by the embryo may be de novo.

The authors thank F. Snyder, Medical and Health Sciences Division, Oak Ridge Associated Universities, Oak Ridge, TN, USA, for encouragement, comments on the manuscript and the gift of $\left[1-{ }^{3} \mathrm{H}\right]$ hexadecanol. We thank S. Fleming for the initial work in setting up the HPLC procedure described. This work was supported by the National Health and Research council of Australia, grant number 890591 .

\section{References}

Alonso, F., Gil, M.G., Sanchez-Crespo, M. \& Mato, J.M. (1982) Activation of 1-alkyl-2-lyso-glycero-3phosphocholine. Acetyl-CoA transferase during phagocytosis in human polymorphonuclear leukocytes. Journal of Biological Chemistry 257, 3376-3378.

Ammit, A.J. \& O'Neill, C. (199I) Comparison of a radioimmunoassay and bioassay for embryo-derived platelet-activating factor. Human Reproduction 6, 872-878.

Battye, K.M., Ammit, A.J., Evans, G. \& O'Neill, C. (199I) Production of platelet activating factor in vitro by preimplantation sheep embryos. Journal of Reproduction and Fertility: 93, 507-514.

Brinster, R.L. (1965) Studies on the development of mouse embryos in vitro. II. The effect of energy source. Journal of Experimental Zoology 158, $59-68$.

Brinster, R.L. (1967) Carbon dioxide production from lactate and pyruvate in the preimplantation mouse embryo. Experimental Cell Research 47, 634-637.

Brinster, R.L. (1969) Incorporation of carbon from glucose and pyruvate into the preimplantation embryo. Experimental Cell Research 58, 153-158.

Bussolino, F., Breviario, F., Aglietta, M., Sanavio, F., Bosia, A. \& Dejana, E. (1987) Studies on the mechanism of interleukin 1 stimulation of platelet activating factor synthesis in human endothelial cells in culture. Biochimica et Biophysica Acta 927, 43-54.
Collier, M., O'Neill, C., Ammit, A.J. \& Saunders, D.M. (1988) Biochemical and pharmacological characterisation of human embryo-derived platelet activating factor. Human Reproduction 3, 993998.

Collier, M., O'Neill, C., Ammit, A.J. \& Saunders, D.M. (1990) Measurement of human embryo-derived platelet-activating factor (PAF) using a quantitative bioassay of platelet aggregation. Human Reproduction 5, 323-328.

Domon, M. (1980) Cell cycle-dependent radiosensitivity in two-cell mouse embryos in culture. Radiation Research 81, 236-245.

Flynn, T.J. \& Hillman, N. (1978) Lipid synthesis from $\left[\mathrm{U}-{ }^{14} \mathrm{C}\right]$ glucose in preimplantation mouse embryos in culture. Biology of Reproduction 19, 922-926.

Gross, R.W. \& Sobel, B.E. (1980) Isocratic highperformance lipid chromatography separation of phosphoglycerides and lysophosphoglycerides. Journal of Chromatography 197, 79-85.

Horrocks, L.A. \& Sharma, M. (1982) Plasmalogens and $O$-alkyl glycerolipids. In Phospholipids, pp. 51-93. Eds J. N. Hawthorne \& G. B. Ansell. Elsevier Biomedical Press, The Netherlands.

Kaye, P.L. (1986) Metabolic aspects of the physiology of the preimplantation embryo. In Experimental Approaches to Mammalian Embryonic Development, pp. 267-292. Eds J. Rossant \& R. A. Pedersen. Cambridge University Press, Cambridge, UK. 
Lee, T-C. (1979) Characterization of fatty alcohol: $\mathrm{NAD}^{+}$oxidoreductase from rat liver. Journal of Biological Chemistry 254, 2892-2896.

Lee, T-C., Malone, B., Blank, M.L., Fitzgerald, V. \& Snyder, F. (1990) Regulation of the synthesis of platelet-activating factor and its inactive storage precursor (1-alkyl-2-acyl-sn-glycero-3-phosphocholine) from 1-alkyl-2-acetyl-sn-glycerol by rabbit platelets. Journal of Biological Chemistry 265, 9181-9187.

Leese, H.J. \& Barton, A.M. (1984) Pyruvate and glucose uptake by mouse ova and preimplantation embryos. Journal of Reproduction and Fertility 72, 9-13.

Lumb, R.H. \& Snyder, F. (1971) A rapid isotopic method for assessing the biosynthesis of ether linkages in glycerolipids of complex systems. Biochimica et Biophysica Acta 244, 217-221.

Mavis, R.D., Bell, R.M. \& Vagelos, P.R. (1972) Effect of phospholipase $\mathrm{C}$ hydrolysis of membrane phospholipids on membraneous enzymes. Journal of Biological Chemistry 247, 2835-2841.

Milligan, S.R. \& Finn, C.A. (1990) Failure of platelet activating factor (PAF-acether) to induce decidualization in mice and failure of antagonists of PAF to inhibit implantation. Journal of Reproduction and Fertility 88, 105-112.

O'Neill, C. (1985) Partial characterisation of the embryoderived platelet-activating factor in mice. Journal of Reproduction and Fertility 75, 375-380.

O'Neill, C. \& Saunders, D.M. (1984) Assessment of embryo quality. Lancet ii, 1305.

O'Neill, C., Gidley-Baird, A.A., Pike, I.L. \& Saunders, D.M. (1987) Use of a quantitative bioassay for embryo-derived platelet activating factor as a means of assessing quality and pregnancy potential of human embryos. Fertility and Sterility 47, 969 .975.

O'Neill, C., Collier, M., Ammit, A.J., Ryan, J.P., Saunders, D.M. \& Pike, I.L. (1989a) Supplementation of in-vitro fertilisation culture medium with platelet activating factor. Lancet ii, 769-772.

O'Neill, C., Collier, M., Ryan, J.P. \& Spinks, N.R. (1989b) Embryo-derived platelet activating factor. Journal of Reproduction and Fertility Supplement 37, 19-27.

O'Neill, C., Wells, X. \& Battye, K. (1990) Embryoderived platelet activating factor: interactions with the arachidonic acid cascade and the establishment of pregnancy. Reproduction Fertility and Development 2, $424-441$

Pike, I.L. \& Wales, R.G. (1982) Uptake and incorporation of glucose especially into glycogen pools of preimplantation mouse embryos during culture in vitro. Australian Journal of Biological Sciences 35, 195-206.

Pratt, H.P.M. (1980) Phospholipid synthesis in the preimplantation embryo. Journal of Reproduction and Fertility 58, 237-248.

Punjabi, U., Vereecken, A., Delbeke, L., Angle, M., Gielis, M., Gerris, J., Johnston, J. \& Buytaert, P. (1990) Embryo-derived platelet activating factor, a marker of embryo quality and viability following ovarian stimulation for in vitro fertilization. Journal of in vitro Fertilization and Embryo Transfer 7, 321-326.

Quinn, P., Warnes, G.M., Kerin, J.F. \& Kirby, C. (1985) Culture factors affecting the success rate of in vitro fertilization and embryo transfer. Annals of the New York Academy of Sciences 442, 195-203.

Renooij, W. \& Snyder, F. (1981) Biosynthesis of 1alkyl-2-acetyl-sn-glycero-3-phosphocholine (platelet activating factor and a hypotensive lipid) by cholinephosphotransferase in various rat tissues. Biochimica et Biophysica Acta 663, 545-556.

Ryan, J.P., Spinks, N.R., O'Neill, C., Ammit, A.J. \& Wales, R.G. (1989) Platelet activating factor (PAF) production by mouse embryos in vitro and its effect on embryonic metabolism. Journal of Cell Biochemistry 40, 387-395.

Ryan, J.P., O'Neill, C. \& Wales, R.G. (1990a) Oxidative metabolism of energy substrates by preimplantation mouse embryos in the presence of platelet activating factor. Journal of Reproduction and Fertility 89, 301-307.

Ryan, J.P., Spinks, N.R., O'Neill, C. \& Wales, R.G. (1990b) Implantation potential and fetal viability of mouse embryos cultured in media supplemented with platelet activating factor. Journal of Reproduction and Fertility 89, 309-315.

Sherman, M.I. (1979) Developmental biochemistry of preimplantation mammalian embryos. Annual Reviews of Biochemistry 48, 443-470.

Snyder, F. (1985) Chemical and biochemical aspects of platelet activating factor: a novel class of acetylated ether-linked choline-phospholipids. Medical Research Review's 5, 107-140.

Snyder, F. (1987) The significance of dual pathways for the biosynthesis of platelet activating factor. 1-Alkyl-2-lyso-sn-glycero-3-phosphate as a branch point. In New Horizons in Platelet Activating Factor Research, pp. 13 25. Eds E. D. Winslow \& M. L. Lee. John Wiley and Sons, Chichester.

Snyder, F. (1990) Platelet-activating factor and related acetylated lipids as potent biologically active cellular mediators. American Journal of Physiology 259, C697-C708.

Spinks, N.R. \& O'Neill, C. (1988) Antagonists of embryo-derived platelet activating factor prevent implantation of mouse embryos. Journal of Reproduction and Fertility 84, 89-98.

Spinks, N.R., Ryan, J.P. \& O'Neill, C. (1990) Antagonists of embryo-derived platelet activating factor act by inhibiting the mouse embryo's capacity for implantation. Journal of Reproduction and Fertility 88, 241-248.

Uemura, Y., Lee, T-C. \& Snyder, F. (1991) A coenzyme A-independent transacylase is linked to the formation of platelet-activating factor (PAF) by generating the lyso-PAF intermediate in the remodeling pathway. Journal of Biological Chemistry 266, 8268-8272.

Wales, R.G. \& Whittingham, D.G. (1970) Metabolism of specifically labelled pyruvate by mouse embryos during culture from the 2-cell stage to the blastocyst. Australian Journal of Biological Sciences 23, 877-887.

Wales, R.G. \& Whittingham, D.G. (1973) The metabolism of specifically labelled lactate and pyruvate by two-cell mouse embryos. Journal of Reproduction and Fertility 33, 207-222. 